\title{
Carcinoembryonic Antigen-Expressing Measles Virus
}

National Cancer Institute

\section{Source}

National Cancer Institute. Carcinoembryonic Antigen-Expressing Measles Virus. NCI

Thesaurus. Code C64775.

An attenuated oncolytic Edmonston (Ed) strain of measles virus (MV) encoding the soluble extracellular N-terminal domain of human carcinoembryonic antigen (CEA) (MVCEA) with potential antineoplastic activity. The cellular receptor of MV is human CD46 antigen, a type 1 integral membrane glycoprotein found on nearly all human tissues and overexpressed on many cancer cell types. Mediated through CD46, both haemagg lutinin and fusion glycoproteins of MV are required for the attachment to and fusion of host cell membranes, thereby leading to syncytia and cell lysis. The expressed CEA, a tumor associated antigen, can be detected in serum and used as a sensitive marker to monitor viral gene expression in order to easily optimize individual therapy. Compared to wild-type $M V$, the Ed strain of MV has a lower affinity for the MV receptor signaling lymphocyteactivation molecule (CD150), mainly expressed in B- and T-lymphocytes, but a higher affinity for CD46. 